\title{
ESTUDO DE CASO
}

\section{E o circo chegou à capital do pequi!}

Seluta Rodrigues de Carvalho, Ione Garcia Altieri, IZABEl BRUnsizian, CÉlIA TERUMI SANDA

0 Circo Lahetô foi uma das 30 entidades finalistas do Prêmio Itaú Unicef $\mathbf{2 0 0 5}$, com o projeto Arte, Circo e Cidadania. A instituição está sediada em Goiânia, Estado de Goiás, e atua há mais de dez anos. Foi fundado por um grupo de artistas e educadores que acreditavam na possibilidade de educar por meio da arte.

\section{Respeitável público, o circo chegou! E parece que para} ficar! A história do Circo, como diz o escritor Torres (1998), vem de longe e pra longe vai. E nossa história não poderia ser diferente.

No picadeiro, artistas milagrosos executam exercícios que parecem até ilógicos se não soubéssemos os sacrifícios que são feitos para consegui-los. Este é o Circo que as crianças amam. Um Circo que faz sonhar com olhos abertos, onde as crianças se sentem adultos e os adultos, mais crianças.

É nesse cenário mágico, na capital de Goiás, que o Circo Lahetô realiza seu trabalho, onde crianças e adolescentes, de sete a 17 anos, alunos de escolas públicas, desenvolvem múltiplas habilidades que vão além do picadeiro. E, do picadeiro, saem para expressar ao mundo seus sonhos e dar o significado que esta arte produz em suas vidas.

\footnotetext{
* Seluta Rodrigues de Carvalho é pedagoga e coordenadora do circo Lahetô; IONE GARCIA ALTIERI, educadora; IZABEL BRUNSIZIAN, psicopedagoga; e CELIA TERUMI SANDA, assistente social, são pesquisadoras
} do CENPEC.

\section{ESPAÇO LÚDICO DE RESPEITO E APOIO}

O Circo Lahetô está sediado no Parque da Criança, espaço revitalizado no centro da cidade de Goiânia, atualmente utilizado por várias organizações nãogovernamentais.

Quiosques, área de preservação permanente, parque infantil com brinquedos educativos, espaços para atividades de esportes, viveiro de mudas nativas do cerrado. Tudo é utilizado em comum pelas instituições parceiras que atuam em diversas áreas e de diferentes maneiras.

A instituição não está só! Uma rede de organizações atua em benefício da criança e do adolescente: a ONG Pró-Cerrado, o Circo Lahetô, Atletas de Jesus, Banco Florestal, Casa da Cultura Digital e Raiz Crepe. Juntos, fundaram a Associação Amigos do Parque que tem como objetivo discutir a qualidade das ações desenvolvidas, o uso das áreas comuns, as questões de legislação em relação à população atendida, buscando contribuir com a formulação e implementação de políticas públicas.

No Parque, também estão instalados o CIMP - Centro Integrado de Apoio Psicopedagógico e a Vara do Juizado da Infância e da Adolescência.

Evidencia-se o constante movimento e a interação entre os coordenadores dos projetos durante as atividades, numa relação de respeito e apoio.

A população atendida pelo Circo reside ao lado do Parque, no Jardim Lobó, área de posse, situada em região de risco, em um vale com enchentes e desabamentos, nas épocas de chuvas, sendo uma das comunidades mais empobrecidas da cidade.

Diante dessa situação, o governo municipal construiu alguns prédios (chamados "predinhos"), transferindo famílias para essa área. Outras foram remanejadas de suas casas, construídas com latas, e passaram a morar em casas menos precárias. 


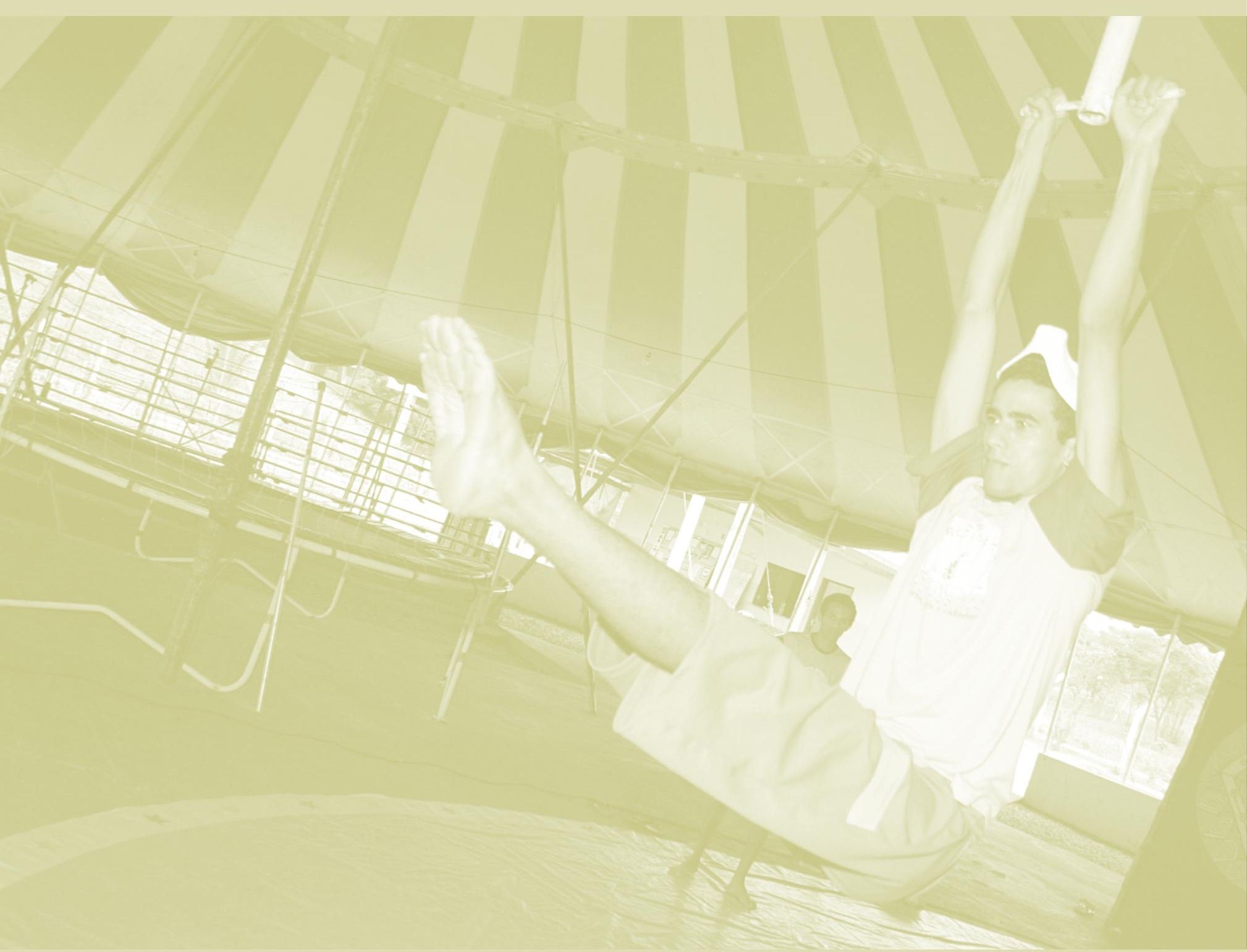

Embaixo da lona colorida, no picadeiro, as crianças e adolescentes experimentam toda fantasia e transformação possível: vale ser palhaço, equilibrista na perna de pau, malabarista, diabolista, acrobata, monociclista, mágico, apresentadores, animadores culturais e muitas outras possibilidades que a imaginação e a criatividade permitirem.

Arte-educadores, que já foram educandos do projeto, contribuem para o desenvolvimento humano integral, incentivam a permanência na escola e promovem o trabalho de iniciação à arte circense, que já atendeu mais de mil crianças e adolescentes, em seus dez anos de existência.
As atividades estimulam a possibilidade de sonhar, exercer sua criatividade, elaborar a confiança e a certeza de ser capaz de reconhecer seus limites, ao dominar equipamentos que antes pareciam impossíveis e inacessíveis. Os desafios do Circo nos remetem às estripulias que os meninos e meninas fazem nas ruas, pois tais equipamentos têm relação direta com o perigo e a aventura.

As atividades podem desenvolver, tanto na criança quanto no adolescente, a compreensão de sua capacidade de movimento corporal, de expressividade, de comunicação com maior inteligência, responsabilidade, equilíbrio e autonomia.

Vale dizer que, no Circo, não se trabalha sozinho. 
Cada número ensaiado mobiliza uma equipe e é um exercício de superação dos limites, especialmente, de convivência grupal.

As crianças e adolescentes têm oportunidade de se desenvolverem de maneira responsável, legitimando seus direitos e estabelecendo relações entre o individual e o coletivo. Com isso, aprendem a ouvir, a opinar e a respeitar as diferentes manifestações. Além de permitir amplas possibilidades de aprendizado, vivenciam preciosos momentos de prazer, de alegria e de boa convivência com o próximo.

No começo de 2006, as professoras da Escola Estadual São Cristóvão, situada próximo à sede do Circo, reuniram-se com os coordenadores do projeto e levantaram os temas que gostariam que fossem trabalhados. Sugeriram os temas de meio ambiente e higiene como motivadores de um projeto conjunto. Ficou estabelecido que cada grupo de alunos da escola visitaria a instituição e participaria das diversas atividades circenses, nos brinquedos e brincadeiras populares e também nas atividades de contação de histórias, de forma dinâmica.

o Circo uniu o seu trabalho diário a essas demandas, utilizando o tema da cooperação e da gentileza, que propõe, por exemplo, que as crianças façam fila para o lanche e observa como se organizam. Em seguida, discute com eles se houve cooperação ou não nesse momento e desafia: "Como é possível formar fila e praticar a gentileza e a cooperação?”, propondo que repitam a atividade.

Em todos os grupos atendidos, uma média de três ou quatro educandos do Circo Lahetô recebem as crianças da escola e apresentam os equipamentos.

O trabalho está em processo de avaliação pelas professoras da Escola e espera-se que o resultado dos encontros seja maior motivação para o estudo e a presença da alegria, uma vez que buscam desenvolver as oficinas de Palhaço (clown).

As professoras já revelam que a vivência no Circo tem se refletido nos textos que as crianças desenvolvem posteriormente à atividade: elas narram o que aprenderam, do que gostaram e do que não gostaram. As crianças que participam cotidianamente do projeto têm mais domínio de certos conteúdos, segundo os professores. Isso se pode notar, por exemplo, na participação de adolescentes em atividades que acontecem em outras cidades, como a cidade de Goiás ou São Paulo, e que retornam com grande repertório apreendido pelos debates e oficinas de que participam. 


\section{EM COOPERAÇÃO, TODOS APRENDEM E FAZEM DE TUDO}

Antes de iniciar o projeto, os coordenadores firmaram parceria com os síndicos dos predinhos, lideranças locais da comunidade e fizeram visitas domiciliares para conhecer as dificuldades de cada família, para efetuar as inscrições das crianças ao projeto.

As crianças passam por todas as atividades - oficinas de malabares, monociclo, bambolé, cama elástica, aula de mágica, de palhaço, perna de pau, diabrete, acrobacia, diabolô e bolinhas - pois se acredita que, num Circo, todos devem conhecer sobre todas as atividades, desde a montagem da lona, o cuidado com os equipamentos, até as apresentações.

Depois, o grupo é incentivado a trocar experiências. "Eles têm que saber todas as técnicas e como o sucesso do Circo é um trabalho de cooperação entre todos, todos aprendem e todos fazem de tudo", dizem os coordenadores das atividades.

Continuam: "A escola de Circo oferece à criança e adolescente que nunca tiveram oportunidade com o lúdico, exercitar a convivência em grupo que é a essência do Circo. Bons espetáculos dependem do outro e isso cria um trabalho de cooperação, com a idéia que um deve torcer pelo sucesso do outro. Todos devem estar juntos! Na hora do espetáculo cada um brilha, todos têm a oportunidade. A idéia é da totalidade!”
O projeto mantém uma ficha individual de cada criança e adolescente e as escolas são visitadas sistematicamente para acompanhamento, junto aos coordenadores das escolas, do aprendizado do aluno.

"O Circo mudou a vida das crianças. Eu os vejo no dia-a-dia, vejo-os fora da escola e do projeto e percebo o quanto eles mudaram. Por isso, sou uma parceira presente", diz a presidente da Associação de Moradores.

Reforça o síndico dos predinhos: "Antes, as crianças perturbavam a organização. Hoje eles cooperam com a minha administração. E por isso estou aqui cooperando e ajudando este projeto a dar certo".

Segundo depoimento de coordenadora pedagógica de uma das escolas estaduais: "A escola de Circo vem dando mais responsabilidade e mais compromisso às crianças e adolescentes. Isso evita evasão escolar. A pedagoga do Circo vem constantemente aqui e discutimos sobre cada aluno".

Uma das alunas do projeto completa: "Moro num abrigo a seis meses. 0 circo é, para mim, um descanso na minha cabeça. Aqui aprendo várias atividades; as atividades aqui do Circo me tiraram o pensamento e sentimento ruim. Eu chorava muito pela minha vida! Agora mudou muito... só tenho alegria. Agora me descobri!"

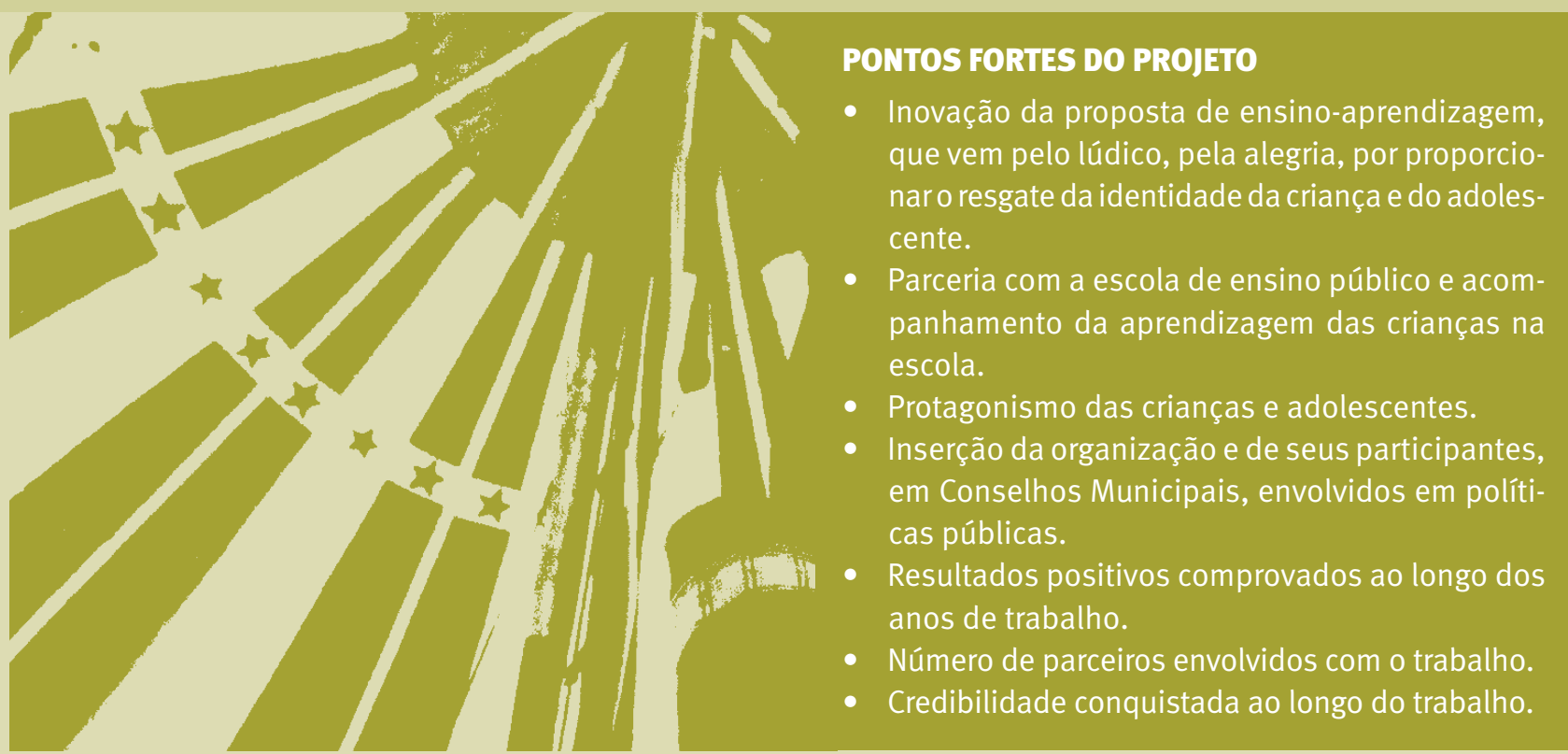




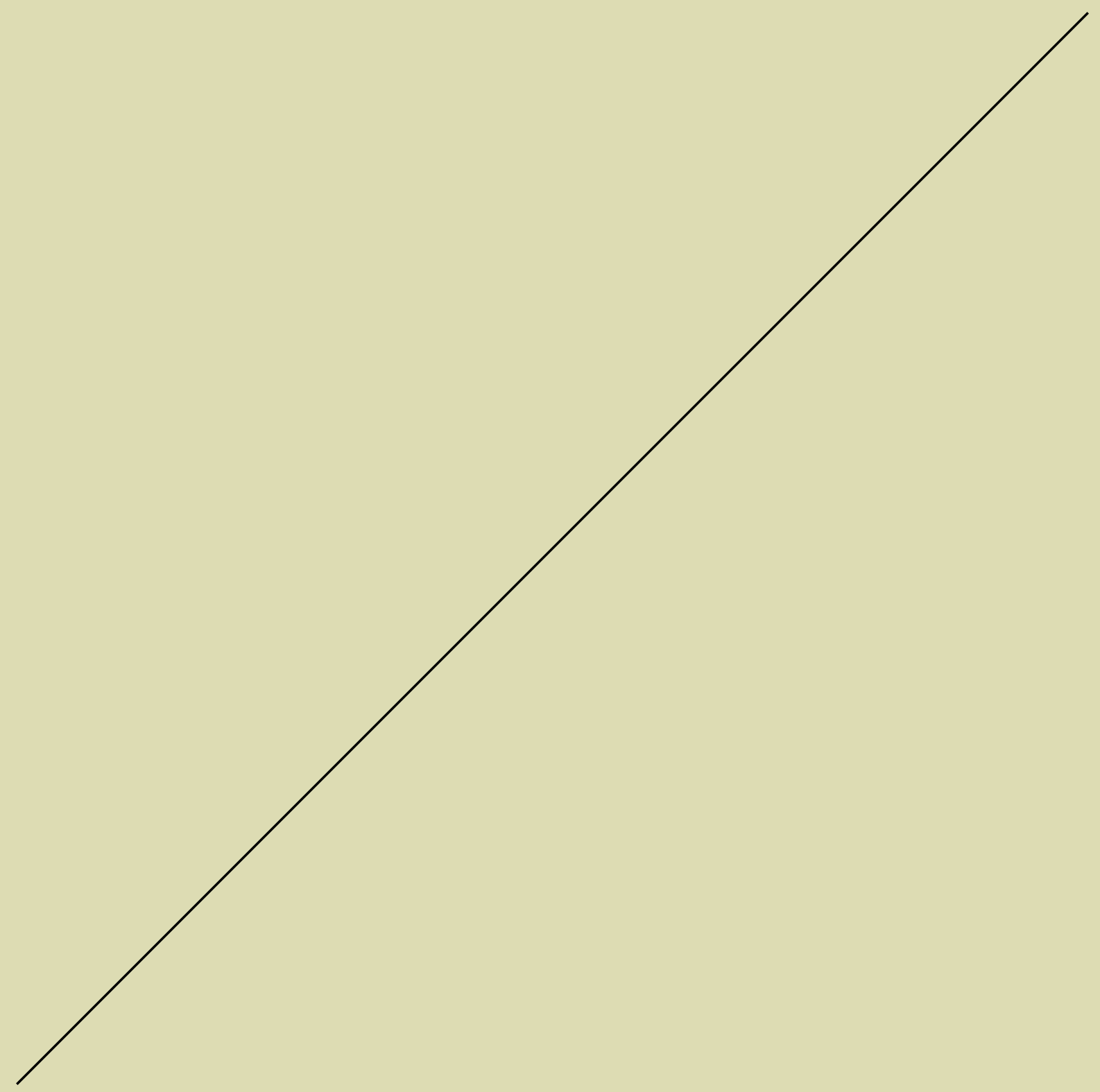

151 CADERNOS CENPEC 2006 n.2 
